\title{
Various Parts of Helianthus annuus Plants as New Sources of Antimalarial Drugs
}

\author{
Wiwied Ekasari (D), ${ }^{1}$ Dwi Widya Pratiwi, ${ }^{1}$ Zelmira Amanda, ${ }^{1}$ Suciati, ${ }^{1}$ \\ Aty Widyawaruyanti ${ }^{D},{ }^{1}$ and Heny Arwati ${ }^{2}$ \\ ${ }^{1}$ Department of Pharmacognosy and Phytochemistry, Faculty of Pharmacy, Universitas Airlangga, Surabaya 60115, Indonesia \\ ${ }^{2}$ Department of Medical Parasitology, Faculty of Medicine, Universitas Airlangga, Surabaya 60115, Indonesia \\ Correspondence should be addressed to Wiwied Ekasari; wiwied-e@ff.unair.ac.id
}

Received 27 June 2019; Revised 16 October 2019; Accepted 11 November 2019; Published 26 November 2019

Guest Editor: Philip F. Uzor

Copyright (c) 2019 Wiwied Ekasari et al. This is an open access article distributed under the Creative Commons Attribution License, which permits unrestricted use, distribution, and reproduction in any medium, provided the original work is properly cited.

\begin{abstract}
Background. Each part of $H$. annuus plants is traditionally used as medicinal remedies for several diseases, including malaria. Antimalarial activity of the leaf and the seed has already been observed; however, there is no report about antimalarial activity of the other parts of $H$. annuus plants. In this study, we assess in vitro and in vivo antimalarial activity of each part of the plants and its mechanism as antimalarial agent against inhibition of heme detoxification. Objective. To investigate the antimalarial activity of various parts of $H$. annuus. Methods. Various parts of the $H$. annuus plant were tested for in vitro antimalarial activity against Plasmodium falciparum 3D7 strain (chloroquine-sensitive), in vivo antimalarial activity against P. berghei using Peters' 4-day suppressive test in BALB/c mice, curative and prophylaxis assay, and inhibition of heme detoxification by evaluating $\beta$-hematin level. Results. Ethanol extract of the roots showed the highest antimalarial activity, followed by ethanol extract of leaves, with $\mathrm{IC}_{50}$ values of $2.3 \pm 1.4$ and $4.3 \pm 2.2 \mu \mathrm{g} / \mathrm{mL}$, respectively and the percentage inhibition of $P$. berghei of $63.6 \pm 8.0$ and $59.3 \pm 13.2$ at a dose of $100 \mathrm{mg} / \mathrm{kg}$, respectively. Ethanol extract of roots produced an $\mathrm{ED}_{50}$ value of $10.6 \pm 0.2 \mathrm{mg} / \mathrm{kg}$ in the curative test and showed an inhibition of $79.2 \%$ at a dose of $400 \mathrm{mg} / \mathrm{kg}$ in the prophylactic assay. In inhibition of heme detoxification assay, root and leaf ethanol extracts yielded a lower $\mathrm{IC}_{50}$ value than positive (chloroquine) control with a value of $0.4 \pm 0.0 \mathrm{and} 0.5 \pm 0.0 \mathrm{mg} / \mathrm{mL}$, respectively. Conclusion. There were promising results of the ethanol extracts of root of $H$. annuus as a new source for the development of a new plant-based antimalarial agent.
\end{abstract}

\section{Introduction}

Most developing countries, including Indonesia, still depend on using plants in traditional medicine, including antimalarial agents. One of these plants is Helianthus annuus (Asteraceae), known as sunflower or "bunga matahari" in local language. Traditionally, each part of $H$. annuus plants is widely used in several healthcare applications, including the treatment of malaria. Sunflower tea is reported to be useful in the treatment of malarial and lung disease [1], and the leaves have long been used in infusion and decoction as traditional remedy for malaria by Ambalabe village community, Madagascar [2].

Muti'ah et al. [3] report that $80 \%$ ethanol extract of $H$. annuus leaf shows good antimalarial activity with an $\mathrm{ED}_{50}$ value of $4.64 \mathrm{mg} / \mathrm{kg}$. Moreover, the combination of $80 \%$ ethanol extract of H. annuus leaf and Acalypha indica Linn. leads to synergetic effect in in vivo antimalarial assay with a $\mathrm{CI}$ value of $0.46(\mathrm{CI}<1)$ and an $\mathrm{ED}_{50}$ value of $1.23 \mathrm{mg} / \mathrm{kg}$ [4]. Intisar et al. [5] also report that methanol and petroleum ether extract from $H$. annuus seeds showed good inhibition activity against $P$. falciparum strain $\mathrm{KI}$ with an $\mathrm{EC}_{50}$ of 0.19 and $0.34 \mu \mathrm{g} / \mathrm{mL}$, respectively.

Based on the data above, it is recognized that $H$. annuus plants are potential source of antimalarial drugs. However, antimalarial activity of the other parts of $H$. annuus plants has not been reported to date. Thus, in this study, we assess in vitro and in vivo antimalarial activity of each part of the plant and its mechanism as antimalarial agent against the inhibition of heme detoxification. The inhibition of heme 
detoxification leads to growth disorder and malaria parasites' mortality as a result of membrane lysis and activity disorder of some enzymes [6-9]. Hence, a substance with high heme detoxification inhibition activity is considered a potential antimalarial agent. Inhibition of heme detoxification is one of the potential biochemical targets, which is possessed by chloroquine and artemisinin [10,11]. The highest antimalarial activity of $H$. annuus plant parts and its ability to inhibit heme detoxification are expected to be obtained through this study as it can be a new source of antimalarial drugs.

\section{Materials and Methods}

2.1. Plant Materials. H. annuus plants were obtained from Oro-oro Ombo, Malang, East Java, Indonesia, in November 2016, and determined by Materia Medica Batu, Malang, East Java. Each part of the plant, including roots, stems, seeds, flowers, and leaves, were air-dried separately. Samples were then ground to powder, once they are completely dried.

2.2. Animal Model. Adult male BALB/c mice with 20-30 g of bodyweight were obtained from Faculty of Veterinary Medicine, Universitas Airlangga. The mice were fed with mice pellet diet and given free access to drink clean water. The animals were allowed to acclimatize for two weeks before being treated. The permission and approval for animal studies were obtained from Faculty of Veterinary Medicine, Universitas Airlangga.

\subsection{Preparation of $96 \%$ Ethanol Extract of $H$. annuus.} Powders from each part of $H$. annuus plants (50 gram) were macerated by $96 \%$ ethanol and then evaporated on a rotary evaporator.

2.4. In Vitro Antimalarial Assay. In this research, cultures of Plasmodium falciparum strain 3D7 (chloroquine-sensitive) were used and cultivated using the Trager and Jensen method [12]. Cultures were cultivated in human $\mathrm{O}^{+}$red blood cells with 5\% hematocrit in RPMI 1640 (Gibco BRL, USA) added with $22.3 \mathrm{mM}$ HEPES (Sigma), hypoxanthine, sodium bicarbonate, and $10 \%$ human $\mathrm{O}^{+}$plasma. Chloroquine diphosphate was used as the positive control.

Antimalarial assay was done using a 24 -well microplate with $1 \%$ initial and experimental parasitaemia $(1 \mathrm{~mL} /$ well of suspension), followed by incubation in a multigas incubator at $37^{\circ} \mathrm{C}$ for 48 hours. The incubated materials were then collected and used to make a thin smear in a glass slide, fixated in methanol, and stained with Giemsa. The number of parasites was then observed under a microscope and compared with the negative control to determine the percentage of parasite growth inhibition. $\mathrm{IC}_{50}$ value was calculated using Probit Analysis.

2.5. In Vivo Antimalarial Activity Assay. Plasmodium berghei strain ANKA was obtained from Eijkman Institute of Molecular Biology, Jakarta, Indonesia. About 20\% of parasitaemia-infected mice were dissected and then the intracardial blood was taken and diluted with the PBS. Each mouse used in this research was inoculated priorly intraperitoneally with $0.2 \mathrm{~mL}$ of solution containing $1 \times 10^{7}$ $P$. berghei-infected erythrocytes [13].

In vivo antimalarial assay of the plant extract was done using Peter's method [14], which had been modified with $100 \mathrm{mg} / \mathrm{kg} /$ day as the selected dose. Thirty-six adult male $\mathrm{BALB} / \mathrm{c}$ mice $(25 \mathrm{~g} \pm 3)$ were inoculated with parasites and randomly grouped into six groups (five treatment groups and one control group), with six mice in each group. Negative control group was treated with $0.5 \%$ sodium carboxymethyl cellulose (Na CMC) suspension. Treatment groups were treated with extract suspension of each part of the plant with the selected dose. Suspension was given orally once a day for 4 days. On the fourth day, a thin blood smear was made from the tail of each mouse, fixated in methanol, and then stained with Giemsa. The thin blood smears were then observed under a microscope to calculate the percentage of parasitaemia and parasite inhibition.

2.6. In Vivo Curative Assay of $96 \%$ Ethanol Extract of H. annuus Roots. Thirty adult male BALB/c mice (8 weeks old) were randomly divided into five groups (six mice per group). Each mouse was infected intraperitoneally with $0.2 \mathrm{~mL}$ of solution containing $1 \times 10^{7} P$. berghei-infected erythrocytes. Negative control (group 1) was treated with $0.5 \% \mathrm{Na}$ CMC suspension. Groups 2, 3, 4, and 5 were treated with $96 \%$ ethanol extract suspension of $H$. annuus root with $1,10,100$, and $250 \mathrm{mg} / \mathrm{kg}$ dose per mouse. Suspension was given orally once a day for 4 days. Percentage of parasitaemia was calculated by making a thin blood smear on the fourth day, which is then fixated in methanol and stained with Giemsa. The calculation was then compared with the control group. $\mathrm{ED}_{50}$ value was obtained by using Probit Analysis.

2.7. In Vivo Prophylaxis Assay of $96 \%$ Ethanol Extract of H. annuus Roots. Thirty adult male BALB/c mice (8 weeks old) were randomly grouped into six groups (five mice per group). Groups 1, 2, 3, and 4 were treated with $96 \%$ ethanol extract suspension of $H$. annuus root with 100, 200, 400, and $800 \mathrm{mg} / \mathrm{kg}$ dose per mouse. Group 5 as the negative control group was treated with $0.5 \% \mathrm{Na}$ CMC suspension, while the positive control (group 6) was given $13 \mathrm{mg} / \mathrm{kg}$ of doxycycline suspension [15]. Each suspension was given orally once a day for 4 days. On the fourth day, each mouse was inoculated with $0.2 \mathrm{~mL}$ of solution containing $1 \times 10^{7} P$. berghei-infected erythrocytes by intraperitoneal injection. Percentage of parasitaemia was determined on the third day by observing the thin blood smear and compared with the control group. Mean survival time of mice in each group was determined during 14 days $\left(\mathrm{D}_{0}-\mathrm{D}_{13}\right)$. Mean survival time was calculated using the following equation:

$$
\text { mean survival time }(\text { MST })=\frac{\text { sum of survival days }}{\text { total observation days }(14)} \times 100 \text {. }
$$


2.8. Heme Detoxification Inhibition Assay. Inhibition of heme detoxification was assessed using the Basilico method [16] with modification. The extract and positive control (chloroquine diphosphate) were diluted with dimethyl sulfoxide (DMSO) a concentration range of $2-0.01 \mathrm{mg} / \mathrm{mL}$. The amount of hematin present in each sample was calculated using a standard curve of hematin dissolved in $0.2 \mathrm{M}$ $\mathrm{NaOH}$. The absorbance was read using the ELISA reader at a wavelength of $405 \mathrm{~nm}$. The effect of each sample against the production of $\beta$-hematin was calculated and compared with the negative control $[17,18]$.

2.9. Statistical Analysis. Data are expressed as mean\pm standard deviation (SD). IC $_{50}$ values were calculated using Probit Analysis. Statistical significance was determined by Kruskal-Wallis nonparametric independent $t$-test and ANOVA (one-way).

\section{Results and Discussion}

$H$. annuus has been planted widely in Indonesia and long been used traditionally as anti-inflammatory, antimalarial, antiasthma, antioxidant, antitumor, and antimicrobial agent. It has been reported that several chemical compounds were already isolated and identified from various parts of this plant, such as heliangolides (sesquiterpene lactones), $\alpha$-pinene, sabinene (monoterpene), helikauranoside (diterpene), and alkaloid and phenolic group in the leaf part; helianthoside (triterpene) and saponin group in the flower part; fatty acid, tocopherol, tannin, and polyphenol group in the seed part; alkaloid and phenolic group in the stem and root parts [1]. Extraction yield from each part of $H$. annuus plants macerated with $96 \%$ ethanol is shown in Table 1.

In vitro screening to observe $P$. falciparum inhibition activity of the plant extract with $\mathrm{IC}_{50}$ value less than $10 \mu \mathrm{g} /$ $\mathrm{mL}$ is an important primary step in the development of new antimalarial drugs. Plant extracts showing $\mathrm{IC}_{50}$ values $\leq 10 \mu \mathrm{g} / \mathrm{mL}$ can be considered to be active, IC $_{50}$ values in the range $10<\mathrm{IC}_{50} \leq 25 \mu \mathrm{g} / \mathrm{mL}$ can be considered to be moderately active, and those exhibiting $\mathrm{IC}_{50}$ values $>25 \mu \mathrm{g} / \mathrm{mL}$ can be considered to be inactive [19]. $\mathrm{IC}_{50}$ values of $96 \%$ ethanol extract of various $H$. annuus plant parts are shown in Table 2. Root extract exhibits the highest in vitro antimalarial activity, followed by leaf and flower extracts with an $\mathrm{IC}_{50}$ value of $2.3 \pm 1.4,4.3 \pm 2.2$, and $4.8 \pm 0.0 \mu \mathrm{g} / \mathrm{mL}$, respectively.

In vivo antimalarial activity was also determined for each extract from various parts of $H$. annuus plants, and the results are shown in Table 3. Ethanol extract of root exhibits the highest percentage inhibition against $P$. berghei, followed by leaf extract with the percentage inhibition of $63.6 \pm 8.0$ and $59.3 \pm 13.2$, respectively.

Method and criteria are varied among the treatment groups examining antimalarial potency of plants by using the rodent animal model. $P$. berghei-infected mice given orally $50-250 \mathrm{mg} / \mathrm{kg} /$ day of extract exhibiting inhibition percentage $>60 \%$ are considered to be active or very active, and those exhibiting inhibition percentage $>30 \%$ are considered to be moderately active [20-24]. In this research, oral
TABLE 1: Extraction yield from various parts of $H$. annuus plants.

\begin{tabular}{lc}
\hline H. annuus plant parts & Extraction yield (\%) \\
\hline Roots & 2.1 \\
Stems & 5.0 \\
Seeds & 2.9 \\
Flowers & 6.7 \\
Leaves & 4.4 \\
\hline
\end{tabular}

administration at a dose of $100 \mathrm{mg} / \mathrm{kg} /$ day of ethanol $H$. annuus extract is used as an initial experiment and observation of parasite growth up to day 4 using mice model.

Based on the first screening of in vivo assay, it is shown that $H$. annuus root extract has the highest activity. Thus, the experiment is continued to assess curative and prophylaxis antimalarial activity of the ethanol root extract of $H$. annuus.

In in vivo curative assay, $P$. berghei-infected mice are treated orally with $96 \%$ ethanol root extract at a dose of 1, 10, 100 , and $250 \mathrm{mg} / \mathrm{kg}$. The results of the 4 -day suppressive test show that the ethanol extract of $H$. annuus root has an $\mathrm{ED}_{50}$ value of $10.6 \pm 0.2 \mathrm{mg} / \mathrm{kg}$ (Table 4). According to Munoz et al. [25], antimalarial activity can be categorized based on the $\mathrm{ED}_{50}$ value, where $\mathrm{ED}_{50}<100 \mathrm{mg} / \mathrm{kg}$ is considered to have very good activity.

In prophylactic effect evaluation of $96 \%$ ethanol $H$. annuus root extract, mice are given a sample orally for 4 days before inoculating with the parasite. The results (see Figure 1) show that the percentage of inhibition parasitaemia in mice treated with the extract at a dose of $400 \mathrm{mg} / \mathrm{kg}$ is higher than that in those treated with $800 \mathrm{mg} / \mathrm{kg}$. Despite that, this result is still lower than that of doxycycline, a standard drug for prophylactic antimalarial in Indonesia.

The $400 \mathrm{mg} / \mathrm{kg}$ dose group shows the highest percentage of prophylactic inhibition (79.2\%) at day 3, and it declines to $62.5 \%$ at a dose of $800 \mathrm{mg} / \mathrm{kg}$. Calabrese and Baldwin [26] report that the upside-down $\mathrm{U}$-curve in the drug activity assessment at different doses may indicate the occurrence of the hormetic effect, which points out to the toxicity of the drug. Aside from the declining percentage of inhibition, the low mean survival time at a dose of $800 \mathrm{mg} / \mathrm{kg}$, compared to 200 and $400 \mathrm{mg} / \mathrm{kg}$ doses, indicates that the $H$. annuus root extract at high dose $(800 \mathrm{mg} / \mathrm{kg})$ tends to have toxicity.

The results of Kruskal-Wallis nonparametric independent $t$-test and one-way ANOVA analysis show that there are significant differences $(p$ value $<0.05)$ in inhibition percentage of the positive control group compared with all the sample groups and the negative control group. There is no significant difference between 100, 200, 400, and $800 \mathrm{mg} /$ $\mathrm{kg}$ doses.

Figure 1 shows that, 96 hours or the fourth day after parasite inoculation, there is an increase in the parasitic growth in the negative dose and control group, whereas in the doxycycline group the parasite growth is relatively stable, which is below $3 \%$. This is thought to be related to the halflife of doxycycline which ranges from 12 to 22 hours $[15,27,28]$ allowing doxycycline to last longer in the body and inhibit the growth of parasites. It is in contrast to extracts or traditional medicines that tend to have a short halflife, such as artemisinin and its derivatives [29, 30]. Based on 
TABLE 2: $\mathrm{IC}_{50}$ values of $96 \%$ ethanol extract of various parts of $H$. annuus plants against $P$. falciparum strain $3 \mathrm{D} 7$.

\begin{tabular}{|c|c|c|c|c|c|c|}
\hline \multirow{2}{*}{ H. annuus plant parts } & \multicolumn{5}{|c|}{$\%$ inhibition at each concentration $(\mu \mathrm{g} / \mathrm{mL})$} & \multirow{2}{*}{$\mathrm{IC}_{50}(\mu \mathrm{g} / \mathrm{mL})$} \\
\hline & 100 & 10 & 1 & 0.1 & 0.01 & \\
\hline Roots & $86.6 \pm 1.7$ & $73.3 \pm 6.9$ & $32.0 \pm 3.7$ & $22.3 \pm 0.0$ & $7.3 \pm 7.4$ & $2.3 \pm 1.4$ \\
\hline Stems & $64.4 \pm 4.6$ & $56.4 \pm 1.1$ & $30.7 \pm 7.7$ & $18.8 \pm 4.9$ & 0 & $10.2 \pm 5.0$ \\
\hline Seeds & $84.4 \pm 1.0$ & $22.2 \pm 6.9$ & $14.2 \pm 3.9$ & $6.2 \pm 10.3$ & 0 & $19.3 \pm 5.5$ \\
\hline Flowers & $85.7 \pm 8.7$ & $48.4 \pm 2.6$ & $32.0 \pm 2.9$ & $19.3 \pm 8.7$ & 0 & $4.8 \pm 0.0$ \\
\hline Leaves & $96.3 \pm 1.8$ & $47.1 \pm 4.7$ & $24.3 \pm 11.7$ & $16.5 \pm 6.2$ & $7.0 \pm 1.0$ & $4.3 \pm 2.2$ \\
\hline
\end{tabular}

TABle 3: Mean percentage of parasitaemia, growth, and inhibition in P. berghei-infected mice treated with $96 \%$ ethanol $H$. annuus extract at a dose of $100 \mathrm{mg} / \mathrm{kg}$ orally once a day for 4 days.

\begin{tabular}{llccc}
\hline \multirow{2}{*}{ H. annuus plant parts } & \multicolumn{2}{c}{ Mean \% parasitaemia } & Mean \% growth & Mean \% inhibition \\
& Day 0 & Day 4 & $3.7 \pm 0.8$ & $63.6 \pm 8.0$ \\
Roots & $0.9 \pm 0.2$ & $4.6 \pm 1.0$ & $6.1 \pm 0.8$ & $40.3 \pm 8.2$ \\
Stems & $1.2 \pm 0.2$ & $7.3 \pm 1.0$ & $6.0 \pm 0.4$ & $41.5 \pm 4.4$ \\
Seeds & $1.0 \pm 0.2$ & $7.1 \pm 0.5$ & $6.6 \pm 0.5$ & $35.9 \pm 4.6$ \\
Flowers & $1.2 \pm 0.5$ & $7.8 \pm 0.4$ & $4.2 \pm 1.4$ & $59.3 \pm 13.2$ \\
Leaves & $0.9 \pm 0.2$ & $5.1 \pm 1.5$ & $10.3 \pm 0.9$ & - \\
Na CMC & $1.6 \pm 0.3$ & $11.8 \pm 0.9$ & & \\
\hline
\end{tabular}

TABLE 4: Mean percentage of parasitaemia, growth, and inhibition against $P$. berghei of $96 \%$ ethanol $H$. annuus root extract compared with control.

\begin{tabular}{|c|c|c|c|c|c|c|}
\hline \multirow[t]{2}{*}{ Sample } & \multirow[t]{2}{*}{ Dose $(\mathrm{mg} / \mathrm{kg})$} & \multicolumn{2}{|c|}{$\begin{array}{c}\text { Mean \% } \\
\text { parasitaemia }\end{array}$} & \multirow[t]{2}{*}{ Mean $\%$ growth } & \multirow[t]{2}{*}{ Mean \% inhibition } & \multirow[t]{2}{*}{$\mathrm{ED}_{50}(\mathrm{mg} / \mathrm{kg})$} \\
\hline & & $\mathrm{D}_{0}$ & $\mathrm{D}_{4}$ & & & \\
\hline \multirow{4}{*}{$96 \%$ ethanol extract of $H$. annuus root } & 1 & $1.1 \pm 0.1$ & $26.2 \pm 1.4$ & $6.3 \pm 0.4$ & $35.8 \pm 4.7$ & \multirow{5}{*}{$10.6 \pm 0.2$} \\
\hline & 10 & $1.0 \pm 0.2$ & $21.2 \pm 0.9$ & $5.1 \pm 0.2$ & $48.3 \pm 2.8$ & \\
\hline & 100 & $1.0 \pm 0.1$ & $15.4 \pm 1.7$ & $3.6 \pm 0.4$ & $64.0 \pm 5.3$ & \\
\hline & 250 & $1.2 \pm 0.4$ & $12.0 \pm 1.8$ & $2.7 \pm 0.4$ & $72.3 \pm 5.3$ & \\
\hline $\mathrm{Na} \mathrm{CMC}$ & - & $1.2 \pm 0.3$ & $40.3 \pm 6.1$ & $9.8 \pm 1.5$ & - & \\
\hline
\end{tabular}

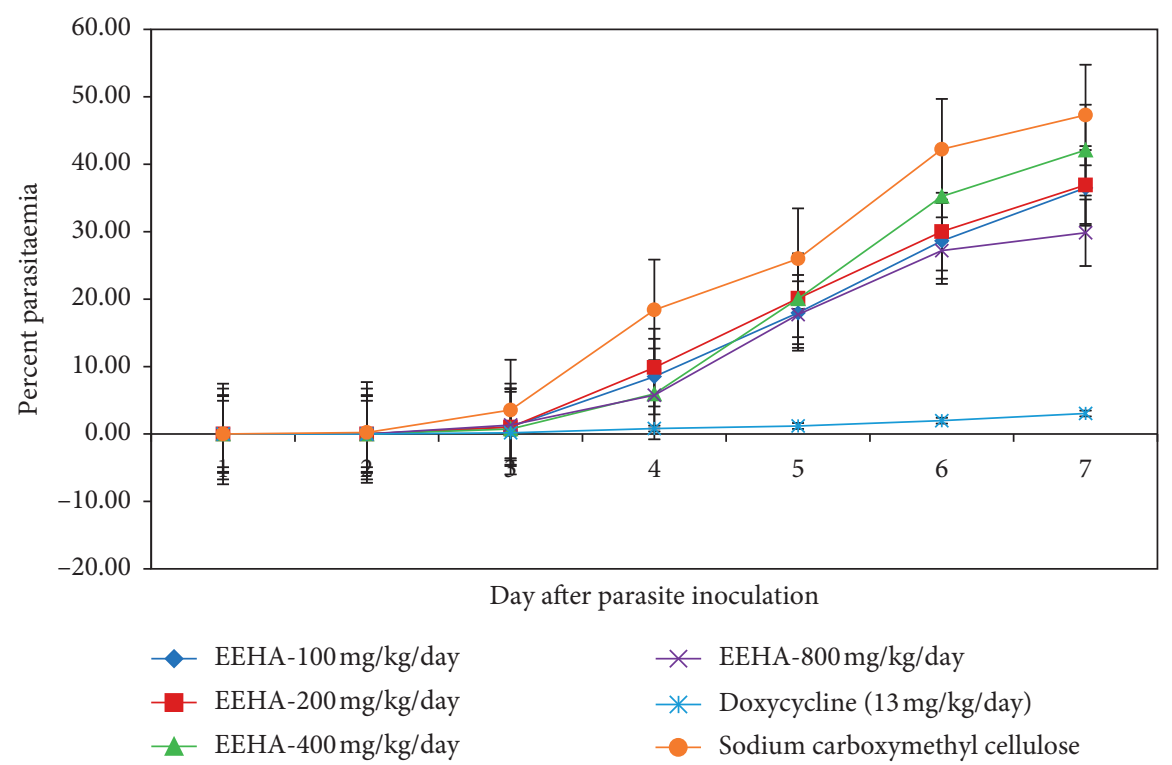

Figure 1: Percentage of parasite growth during seven days after inoculation with parasites on in vivo prophylaxis assay of $96 \%$ ethanol extract of $H$. annuus roots. Average values and standard deviations from five mice per drug/dose are also shown. $p$ value $<0.05$. $\mathrm{EEHA}=$ ethanolic extract of $H$. annuus. 
TABLe 5: Results of heme detoxification inhibition assay of the $96 \%$ ethanol extract of each part of the $H$. annuus plant.

\begin{tabular}{|c|c|c|c|c|}
\hline Sample & Concentration $(\mathrm{mg} / \mathrm{mL})$ & Mean value of hematin $(\mathrm{mM})$ & Mean \% inhibition & $\mathrm{IC}_{50}(\mathrm{mg} / \mathrm{mL})$ \\
\hline Negative control & - & $121.0 \pm 2.6$ & - & \multirow{7}{*}{$0.4 \pm 0.0$} \\
\hline \multirow{6}{*}{$96 \%$ ethanol extract of root } & 2.00 & $34.2 \pm 1.2$ & $71.7 \pm 1.0$ & \\
\hline & 1.00 & $44.6 \pm 1.2$ & $63.1 \pm 1.0$ & \\
\hline & 0.50 & $58.3 \pm 1.1$ & $51.8 \pm 0.9$ & \\
\hline & 0.25 & $67.6 \pm 1.3$ & $44.1 \pm 1.1$ & \\
\hline & 0.10 & $81.8 \pm 1.3$ & $32.3 \pm 1.1$ & \\
\hline & 0.01 & $99.8 \pm 2.2$ & $17.5 \pm 1.8$ & \\
\hline \multirow{6}{*}{$96 \%$ ethanol extract of seed } & 2.00 & $61.6 \pm 1.4$ & $49.1 \pm 1.1$ & \multirow{6}{*}{$2.4 \pm 0.2$} \\
\hline & 1.00 & $71.0 \pm 1.2$ & $41.3 \pm 1.0$ & \\
\hline & 0.50 & $84.9 \pm 3.3$ & $29.8 \pm 2.8$ & \\
\hline & 0.25 & $97.3 \pm 2.3$ & $19.6 \pm 1.9$ & \\
\hline & 0.10 & $105.5 \pm 1.3$ & $12.8 \pm 1.1$ & \\
\hline & 0.01 & $114.1 \pm 1.8$ & $5.7 \pm 1.5$ & \\
\hline \multirow{6}{*}{$96 \%$ ethanol extract of flower } & 2.00 & $46.8 \pm 1.1$ & $61.4 \pm 0.9$ & \multirow{6}{*}{$0.9 \pm 0.1$} \\
\hline & 1.00 & $55.7 \pm 1.3$ & $53.9 \pm 1.1$ & \\
\hline & 0.50 & $68.4 \pm 0.9$ & $43.4 \pm 0.7$ & \\
\hline & 0.25 & $81.8 \pm 0.9$ & $32.4 \pm 0.7$ & \\
\hline & 0.10 & $89.8 \pm 0.9$ & $25.8 \pm 0.8$ & \\
\hline & 0.01 & $99.3 \pm 1.2$ & $17.9 \pm 1.0$ & \\
\hline \multirow{6}{*}{$96 \%$ ethanol extract of leaf } & 2.00 & $38.6 \pm 0.9$ & $68.1 \pm 0.7$ & \multirow{6}{*}{$0.5 \pm 0.0$} \\
\hline & 1.00 & $48.9 \pm 0.8$ & $59.6 \pm 0.7$ & \\
\hline & 0.50 & $62.0 \pm 1.1$ & $48.7 \pm 0.9$ & \\
\hline & 0.25 & $75.5 \pm 1.4$ & $37.6 \pm 1.1$ & \\
\hline & 0.10 & $83.5 \pm 0.6$ & $31.0 \pm 0.5$ & \\
\hline & 0.01 & $98.1 \pm 0.9$ & $18.9 \pm 0.7$ & \\
\hline \multirow{6}{*}{$96 \%$ ethanol extract of stem } & 2.00 & $140.1 \pm 9.2$ & $53.7 \pm 3.1$ & \multirow{6}{*}{$1.9 \pm 0.5$} \\
\hline & 1.00 & $179.8 \pm 5.6$ & $40.6 \pm 1.8$ & \\
\hline & 0.50 & $206.3 \pm 8.3$ & $31.8 \pm 2.8$ & \\
\hline & 0.25 & $241.8 \pm 3.6$ & $20.1 \pm 1.2$ & \\
\hline & 0.10 & $264.7 \pm 3.6$ & $12.5 \pm 1.2$ & \\
\hline & 0.01 & $288.0 \pm 5.5$ & $4.8 \pm 1.8$ & \\
\hline \multirow{6}{*}{ Chloroquine diphosphate } & 2.00 & $40.4 \pm 2.1$ & $66.6 \pm 1.7$ & \multirow{6}{*}{$0.6 \pm 0.0$} \\
\hline & 1.00 & $50.9 \pm 0.6$ & $57.9 \pm 0.5$ & \\
\hline & 0.50 & $64.3 \pm 0.9$ & $46.8 \pm 0.7$ & \\
\hline & 0.25 & $77.0 \pm 0.8$ & $36.3 \pm 0.7$ & \\
\hline & 0.10 & $85.3 \pm 1.2$ & $29.4 \pm 1.0$ & \\
\hline & 0.01 & $94.6 \pm 0.7$ & $21.8 \pm 0.6$ & \\
\hline
\end{tabular}

the antimalarial test results of $H$. annuus root in vivo, it can be concluded that the $96 \%$ ethanol extract of $H$. annuus root has more potential activities as curative antimalarial than prophylactic.

One of the potential biochemical targets for the development of new antimalarial drugs is heme detoxification. The results of heme detoxification inhibition assay (see Table 5) show that the $96 \%$ ethanol extract of $H$. annuus root $\left(\mathrm{IC}_{50}=0.4 \pm 0.0 \mathrm{mg} / \mathrm{mL}\right)$ and leaf $\left(\mathrm{IC}_{50}=0.5 \pm 0.0 \mathrm{mg} / \mathrm{mL}\right)$ has higher activity than chloroquine diphosphate, a standard antimalarial drug $\left(\mathrm{IC}_{50}=0.6 \pm 0.0 \mathrm{mg} / \mathrm{mL}\right)$.

It was reported that free heme is toxic to parasites as it causes lysis of the parasite vacuolar membrane [31]. Thus, malaria parasites develop heme detoxification mechanism to change the toxic heme into a harmless one. The inhibition of heme detoxification leads to growth disorder and malaria parasites mortality as a result of membrane lysis and activity disorder of some enzymes [6-9].
Based on the entire assay undertaken in this research, it is established that the ethanol extract of $H$. annuus root shows the highest antimalarial activity among the other parts of plants, either in in vitro, in vivo, or in heme detoxification inhibition assay. Therefore, the ethanol extract of $H$. annuus root is a potential source of new antimalarial drugs from natural resources.

\section{Conclusion}

Based on the results of the study, they show that $96 \%$ ethanol extract of $H$. annuus root has the highest antimalarial activity compared to stems, seeds, flowers, and leaves of $H$. annuus. $96 \%$ ethanol extract of $H$. annuus root has more potential activity as a curative antimalarial drug than a prophylactic one. Similarly, for the antimalarial mechanism in inhibiting heme detoxification, 96\% ethanol extract of $H$. annuus root has the greatest inhibitory activity compared 
to the other parts of $H$. annuus; even the inhibition is greater than chloroquine, a standard drug. So, it can be concluded that the $96 \%$ ethanol extract of $H$. annuus root contains a potential antimalarial substance which is a new source for the development of a new plant-based antimalarial agent.

\section{Data Availability}

All data are included within the manuscript.

\section{Conflicts of Interest}

The authors declare that they have no conflicts of interest.

\section{Acknowledgments}

The authors would like to thank "Riset Mandat" of Universitas Airlangga Scheme for financial support.

\section{References}

[1] S. Saini and S. Sharma, "Helianthus annuus (Asteracea): a review," International Journal of Pharma Professional's Research, vol. 2, no. 4, pp. 381-386, 2011.

[2] N. H. Rakotoarivelo, F. Rakotoarivony, A. V. Ramarosandratana et al., "Medicinal plants used to treat the most frequent diseases encountered in Ambalabe rural community, Eastern Madagascar," Journal of Ethnobiology and Ethnomedicine, vol. 11, no. 1, p. 68, 2015.

[3] R. Muti'ah, E. K. Hayati, and Khairunnisak, "The effectivity of ethanolic extract sunflower leaves (Helianthus annuus) as anti-malarial agent against Plasmodium berghei," in Proceedingsof the International Conference, The 4th Green Technology Faculty of Science and Technology, Islamic of University State Maulana Malik Ibrahim Malang, Malang, Indonesia, November 2013.

[4] K. Ngibad, "The effectiveness of the combination of ethanol extract of sunflower leaves (Helianthus annuus) and antinganting (Acalypha indica Linn) as an antimalarial in vivo," Journal of Galician Pharmacy, vol. 5, no. 1, pp. 12-19, 2019.

[5] E. M. Intisar, E. K. Hassan, A. M. Salah et al., "Anti-malarial activity of some medicinal Sudanese plants," Journal of Forest Products and Industries, vol. 3, no. 6, pp. 236-240, 2014.

[6] I. W. Sherman, Malaria, Parasite Biology, Pathogenesis and Protection, ASM Press, Washington, DC, USA, 1998.

[7] H. L. Ziegler, D. Staerk, J. Christensen, L. Hviid, H. Hagerstrand, and J. W. Jaroszewski, "In vitro Plasmodium falciparum drug sensitivity assay: inhibition of parasite growth by incorporation of stomatocytogenic amphiphiles into erythrocyte membrane," Antimicrobial Agents and Chemotherapy, vol. 46, no. 5, pp. 1441-1446, 2002.

[8] S. Auparakkitanon, W. Noonpakdee, R. K. Ralph, W. A. Denny, and P. Wilairat, "Antimalarial 9-anilinoacridine compound directed at hematin," Antimicrobial Agents and Chemotherapy, vol. 47, no. 12, pp. 3708-3712, 2003.

[9] B. Tekwani and L. Walker, "Targeting the hemozoin synthesis pathway for the new antimalarial drug discovery: technologies for in vitro $\beta$-hematin formation assay," Combinatorial Chemistry \& High Throughput Screening, vol. 8, no. 1, pp. 63-79, 2005.

[10] A. V. Pandey, H. Bisht, V. K. Babbarwal, J. Srivastava, K. C. Pandey, and V. S. Chauhan, "Mechanism of malarial haem detoxification inhibition by chloroquine," Biochemical Journal, vol. 355, no. 2, pp. 333-338, 2001.

[11] A. V. Pandey, B. L. Tekwani, R. L. Singh, and V. S. Chauhan, "Artemisinin, and endoperoxide antimalarial, disrupts the hemoglobin catabolism and heme detoxification systems in malarial parasite," Journal of Biological Chemistry, vol. 274, no. 27, pp. 19383-19388, 1999.

[12] W. Trager and J. Jensen, "Human malaria parasites in continuous culture," Science, vol. 193, no. 4254, pp. 673-675, 1976.

[13] W. Ekasari, T. S. Wahyuni, H. Arwati, and N. T. Putri, "Determination of effective dose of antimalarial from Cassia spectabilis leaf ethanol extract in Plasmodium berghei-infected mice," African Journal of Infectious Disease, vol. 12, no. suppl. 1, pp. 110-115, 2018.

[14] W. Peters, J. H. Portus, and B. L. Robinson, "The chemotherapy of rodent malaria. XXII. The value of drug-resistant strains of $P$. berghei in screening for blood schizontocidal activity," Annals of Tropical Medicine \& Parasitology, vol. 69, no. 2, pp. 155-171, 1975.

[15] K. R. Tan, A. J. Magill, P. M. Arguin, and M. E. Parise, "Doxycycline for malaria chemoprophylaxis and treatment: report from the CDC expert meeting on malaria chemoprophylaxis," The American Journal of Tropical Medicine and Hygiene, vol. 84, no. 4, pp. 517-531, 2011.

[16] N. Basilico, E. Pagani, D. Monti et al., "A microtitre-based method for measuring the haem polymerization inhibitory activity (HPIA) of antimalarial drugs," Journal of Antimicrobial Chemotherapy, vol. 42, no. 1, pp. 55-60, 1998.

[17] T. S. Macedo, L. Colina-Vegas, M. Da Paixão et al., "Chloroquine-containing organoruthenium complexes are fastacting multistage antimalarial agents," Parasitology, vol. 143, no. 12, pp. 1543-1556, 2016.

[18] S. Joshi, R. Munshi, G. Talele et al., "An experimental in vitro study to evaluate the antimalarial activity of select homeopathy preparations," International Journal of Medical and Health Research, vol. 3, no. 7, pp. 65-68, 2017.

[19] R. B. S. Lima, L. F. Rocha e Silva, M. R. S. Melo et al., "In vitro and in vivo anti-malarial activity of plants from the Brazilian Amazon," Malaria Journal, vol. 14, no. 1, p. 508, 2015.

[20] L. F. Rocha e Silva, K. L. Nogueira, A. C. da Silva Pinto et al., "In vivo antimalarial activity and mechanisms of action of 4nerolidylcatechol derivatives," Antimicrobial Agents and Chemotherapy, vol. 59, no. 6, pp. 3271-3280, 2015.

[21] H. C. Upadhyay, B. S. Sisodia, J. Agrawal, A. Pal, M. P. Darokar, and S. K. Srivastava, "Antimalarial potential of extracts and isolated compounds from four species of genus Ammannia," Medicinal Chemistry Research, vol. 23, no. 2, pp. 870-876, 2014.

[22] M. F. Musila, S. F. Dossaji, J. M. Nguta, C. W. Lukhoba, and J. M. Munyao, "In vivo antimalarial activity, toxicity and phytochemical screening of selected antimalarial plants," Journal of Ethnopharmacology, vol. 146, no. 2, pp. 557-561, 2014.

[23] J. M. Nguta and J. M. Mbaria, "Brine shrimp toxicity and antimalarial activity of some plants traditionally used in treatment of malaria in Msambweni district of Kenya," Journal of Ethnopharmacology, vol. 148, no. 3, pp. 988-992, 2013.

[24] J. W. Gathirwa, G. M. Rukunga, P. G. Mwitari et al., "Traditional herbal antimalarial therapy in Kilifi district, Kenya," Journal of Ethnopharmacology, vol. 134, no. 2, pp. 434-442, 2011. 
[25] V. Muñoz, M. Sauvain, G. Bourdy et al., "The search for natural bioactive compounds through a multidisciplinary approach in Bolivia. Part II. Antimalarial activity of some plants used by Mosetene Indians," Journal of Ethnopharmacology, vol. 69, no. 2, pp. 139-155, 2000.

[26] E. J. Calabrese and L. A. Baldwin, "Hormesis: U-shaped dose responses and their centrality in toxicology," Trends in Pharmacological Sciences, vol. 22, no. 6, pp. 285-291, 2001.

[27] B. A. Cunha, J. B. Comer, and M. Jonas, "The tetracyclines," Medical Clinics of North America, vol. 66, no. 1, pp. 293-302, 1982.

[28] P. G. Welling, P. A. Koch, C. C. Lau, and W. A. Craig, "Bioavailability of tetracycline and doxycycline in fasted and nonfasted subjects," Antimicrobial Agents and Chemotherapy, vol. 11, no. 3, pp. 462-469, 1977.

[29] Z. Guo, "Artemisinin anti-malarial drugs in China," Acta Pharmaceutica Sinica B, vol. 6, no. 2, pp. 115-124, 2016.

[30] K. Karunamoorthi, S. Sabesan, K. Jegajeevanram, and J. Vijayalakshmi, "Role of traditional antimalarial plants in the battle against the global malaria burden," Vector-Borne and Zoonotic Diseases, vol. 13, no. 8, pp. 521-544, 2013.

[31] A. C. Chou and C. D. Fitch, "Mechanism of hemolysis induced by ferriprotoporphyrin IX," Journal of Clinical Investigation, vol. 68, no. 3, pp. 672-677, 1981. 


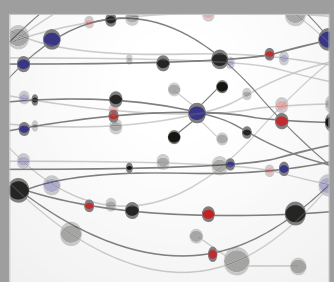

The Scientific World Journal
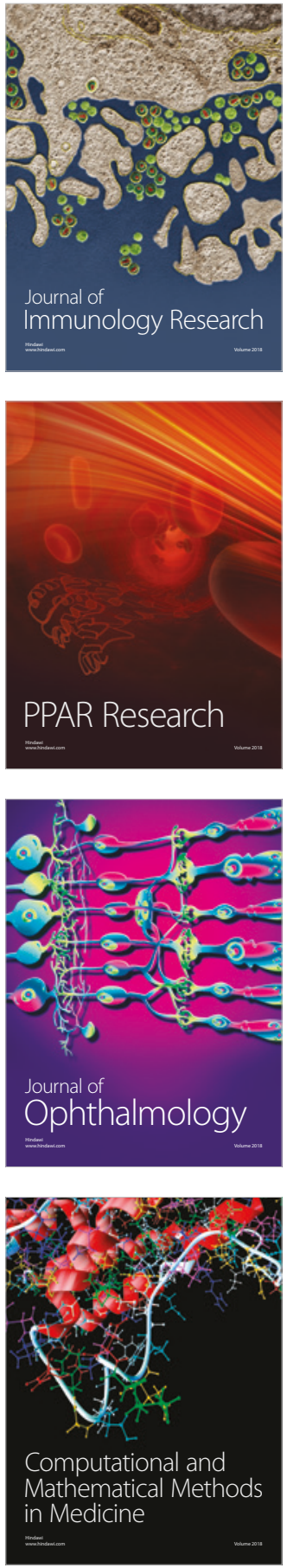

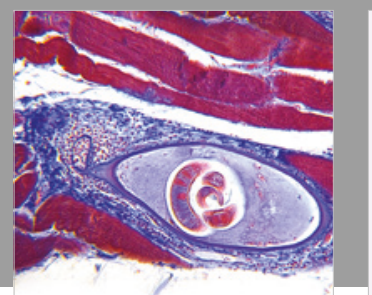

Gastroenterology Research and Practice

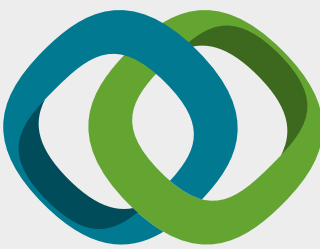

\section{Hindawi}

Submit your manuscripts at

www.hindawi.com
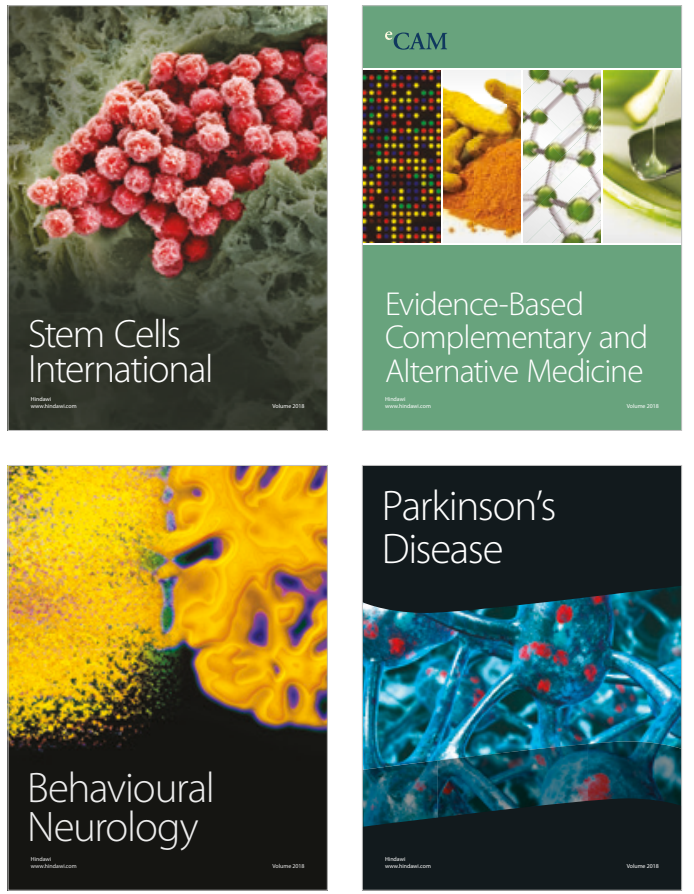

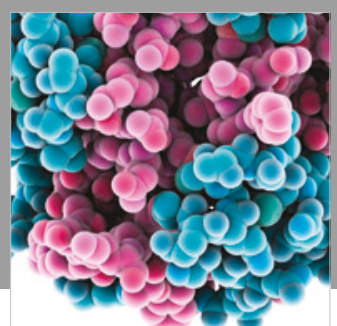

ournal of

Diabetes Research

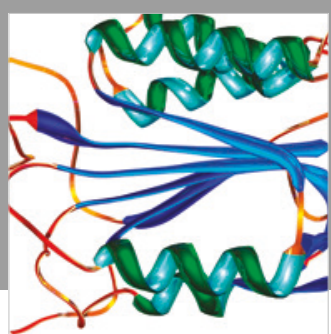

Disease Markers
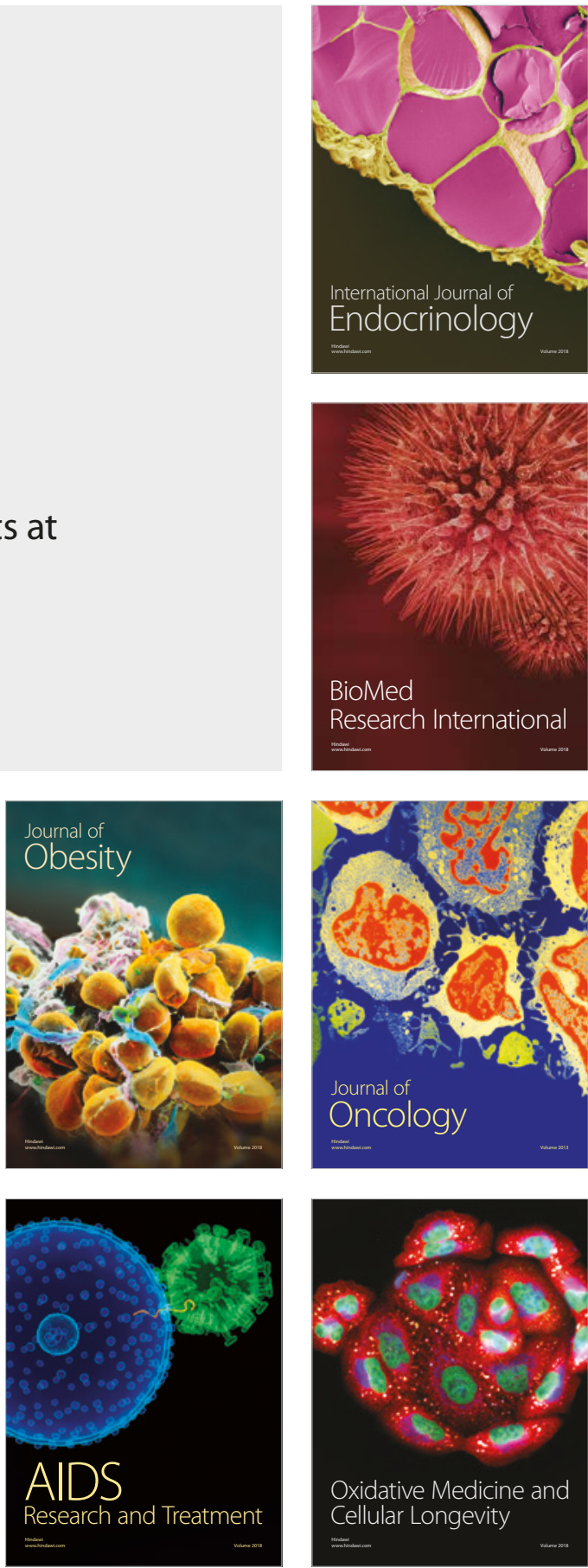